ECCOMAS

Proceedia
COMPDYN 2021

$8^{\text {th }}$ ECCOMAS Thematic Conference on Computational Methods in Structural Dynamics and Earthquake Engineering

M. Papadrakakis, M. Fragiadakis (eds.)

\title{
ROLE OF DESIGN LEVEL AND INFILL ARRANGEMENT ON THE SEISMIC FRAGILITY CURVES OF ITALIAN RC EXISTING BUILDINGS
}

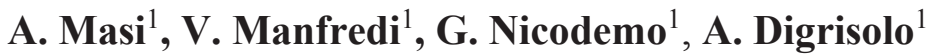 \\ ${ }^{1}$ University of Basilicata - School of Engineering - Viale dell'Ateneo Lucano, 10 - 85100 Potenza - \\ Italy \\ \{angelo.masi, vincenzo.manfredi, giuseppe.nicodemo, andrea.digrisolo\}@unibas.it
}

\begin{abstract}
Assessing the seismic vulnerability of existing buildings is a fundamental step in order to define mitigation programs in prone earthquake areas. In Italy, in 2019 the National Department of Civil Protection supported an ongoing research project involving its "Center of Competence" on seismic risk, ReLUIS (Network of University Laboratories for Earthquake Engineering), with the cooperation of Eucentre (European Centre for Training and Research in Earthquake Engineering) to update the 2018 version of the National Risk Assessment. In this context, new fragility curves are being derived by using different approaches, whose results will be properly combined. In the paper, the purposely set up methodology for deriving analytical fragility curves through Non-Linear Dynamic Analyses (NLDAs) has been described. Further, results relevant to some Italian Reinforced Concrete $(R C)$ building types have been shortly presented and analyzed, emphasizing the role of some key parameters affecting seismic vulnerability such as design level and infill arrangement.
\end{abstract}

Keywords: RC existing buildings, seismic vulnerability assessment, non-linear dynamic analyses, fragility curves

ISSN:2623-3347 (C) 2021 The Authors. Published by Eccomas Proceedia.

Peer-review under responsibility of the organizing committee of COMPDYN 2021.

doi: $10.7712 / 120121.8704 .19325$ 


\section{INTRODUCTION}

Past earthquakes have clearly pointed out the high level of seismic risk in Italy. According to the 2018 National Risk Assessment (NRA) [1,2] released by the Department of Civil Protection (DPC), seismic risk mainly depends on the high vulnerability of the existing building stock, which was mostly built before the seismic classification of large part of the Italian territory and, consequently, without seismic rules. Seismic risk analyses in the 2018 NRA were carried out through the "Italian Risk MAps" (IRMA) platform [3], by combining the results obtained by different research units (RUs) belonging to two "Centers of Competence" of DPC, such as ReLUIS (Network of University Laboratories for Earthquake Engineering) and Eucentre (European Centre for Training and Research in Earthquake Engineering). These results are mostly based on the empirical information reported in the Da.D.O. (Database of Observed Damage) database [4] collecting damage data relevant to the most damaging Italian earthquakes occurred in the last fifty years. Within the ongoing 2019-2021 DPC-ReLUIS research project, the Work Package WP4 "Seismic Risk Maps - MARS" aims at preparing an updated version of the 2018 NRA by considering additional vulnerability models [5]. Specifically, in order to overcome the limited amount of observational damage data, in particular for Reinforced Concrete (RC) buildings, new sets of fragility curves (FCs) are being derived by using different approaches whose results will be properly combined [5]. In the present paper, the methodology for deriving analytical FCs especially for RC buildings through Non-Linear Dynamic Analyses (NLDAs) has been briefly described. Subsequently, the results for some RC building types have been analyzed in order to highlight the role of some key parameters affecting seismic vulnerability such as design level (i.e., gravity load design and earthquake resistant design) and infill arrangement (i.e., infills regularly arranged along the height and pilotis configuration).

\section{METHODOLOGY}

In the MARS research activity, a cloud-like approach has been adopted for deriving analytical Fragility Curves (FCs) through Non-Linear Dynamic Analyses (NLDAs). The methodology is based on ten main steps, as follows:

1. Identification of building classes

2. Selection of building types

3. Simulated design of building types

4. Modelling

5. Selection of Intensity Measure

6. Selection of representative ground-motion records

7. Non-linear dynamic analyses

8. Definition of relationship "structural response - damage level"

9. Treatment of fragility curves dispersion

10. Generation of analytical fragility curves

In order to identify building classes and typologies (steps 1-2), the knowledge of the attributes mainly affecting seismic vulnerability and its distribution over a building stock are crucial aspects in large-scale vulnerability studies [6, 7]. In this context, several sources of information are available in Italy (e.g., ISTAT census data [8], post-earthquake inspections [9], interviewbased surveys [10]), each one characterized by different quality and accuracy of data. According to the 2011 ISTAT census of population and houses [8], the Italian building stock amounts to about 12 million buildings, most of them are masonry structures (more than 7 million) while about 4 million are RC ones. Due to the large number of masonry structures, almost half of the 
Italian buildings have 2 storeys (i.e., low-rise type) while, for taller buildings, RC resisting frame structures were generally adopted. In terms of construction period, masonry buildings were mostly built up to the end of the 1970s while RC buildings became the structural type mainly adopted in Italy after the 1970s. Due to the low percentage of the Italian territory classified as seismic until 1980 (about 25\%), most of the existing residential buildings were designed only for gravity loads. In case of seismic design, moderate lateral forces (i.e., equal to either $7 \%$ or $10 \%$ of the "seismic weight") without anti-seismic criteria were used. Generally, both materials' quality and design practice have growth over time. Similarly, as a result of the increasing attention to thermal and sound insulation requirements, different types of infills can be found, as reported in [11].

Summarizing the previous remarks, analytical FCs for Italian RC buildings have been derived by considering the following parameters (Figure 1):

- period of construction, three periods: '50s, '70s and '90s (consistent with the ranges 194670, 1971-90 and >1991 defined by ISTAT 2011);

- design level, two types: GLD buildings (i.e., designed only for gravity loads) and ERD buildings (i.e., earthquake resistant design);

- number of storeys, three types: Low-rise (i.e., 1-2 storeys, Figure 2a,d), Mid-rise (i.e., 3-5 storeys, Figure $2 b, e)$ and High-rise ( $\geq 6$ storeys, Figure $2 c, e)$;

- infill arrangement, three types: Regularly Infilled-frame (IF); Pilotis-frame (PF) and Bare frame $(\mathrm{BF})$.

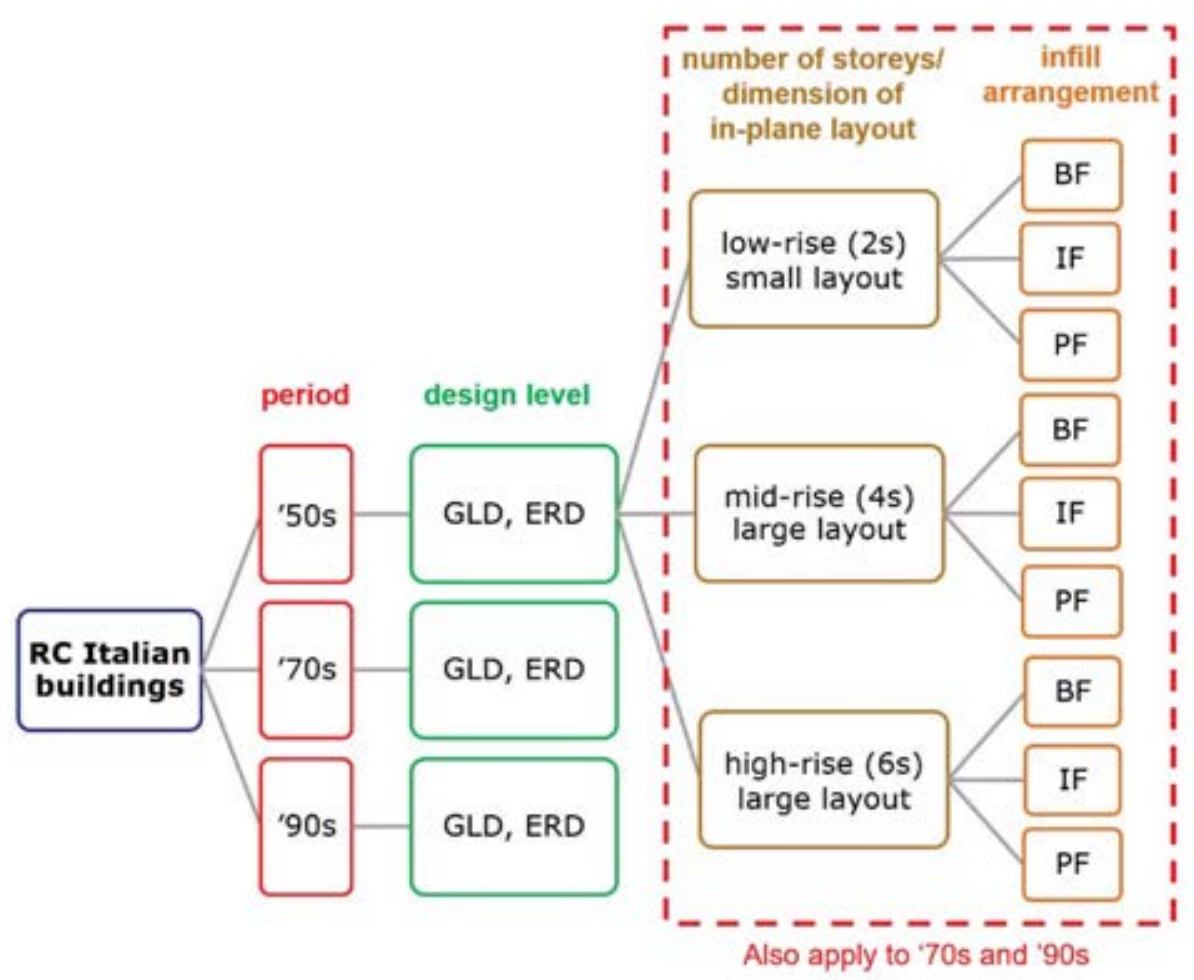

Figure 1: RC building types (from Masi et al. [5])

According to the above reported parameters, some building prototypes have been selected and detailed by means of the simulated design [12] carried out by taking into account the code in force, the quality of the typical materials and the design practice of the period. The selected structural layout is regular in-plan with different dimensions for low rise (Figure 2a,d) and $\mathrm{mid} / \mathrm{high}$ rise (Figure $2 \mathrm{~b}, \mathrm{c}, \mathrm{e}$ ) types. For the ' $50 \mathrm{~s}$ and ' 70 s building types (both GLD and ERD 
types), lateral load resisting frames (i.e., having rigid beams) are present only along the $\mathrm{X}$ direction and on the exterior frames. On the contrary, the ' 90 s types show two frames (with flexible internal beams) along the two orthogonal in-plan directions. For all the considered building types, infills are double layers with empty cavity having different effective thickness (from 20 to $28 \mathrm{~cm}$, ranging from ' $50 \mathrm{~s}$ to ' 90 s types) values and consistency (i.e., solid and hollow clay bricks).

Structural analyses have been performed by using the finite element code OpenSees [13]. A macro-modelling based on lumped plasticity has been adopted according to Ricci et al. [14]. Specifically, at both ends of each structural member, a bending moment-rotation (M- $\theta$ ) relationship has been defined by adopting the Ibarra, Medina and Krawinkler model [15]. When a brittle failure is predicted (e.g., this typically occurs in the short columns of the staircase structure), the above-mentioned $\mathrm{M}-\theta$ relationship has been appropriately modified considering a bending moment value calculated as a function of the ultimate shear capacity according to the Sezen model [16]. On the basis of the mechanical properties of the constituent materials typically found in real buildings of the period under consideration $[17,18]$, mean strength values have been assumed in evaluating the structural capacity. Infill panels have been modelled by using an equivalent diagonal whose mechanical properties has been assumed according to [11, 19].

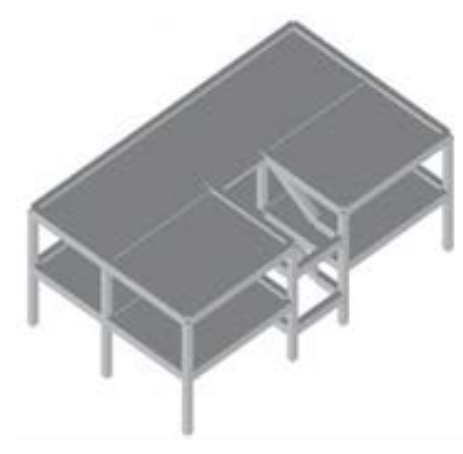

a)

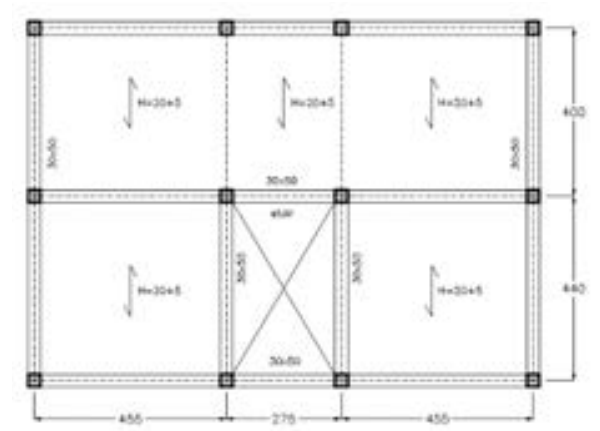

d)

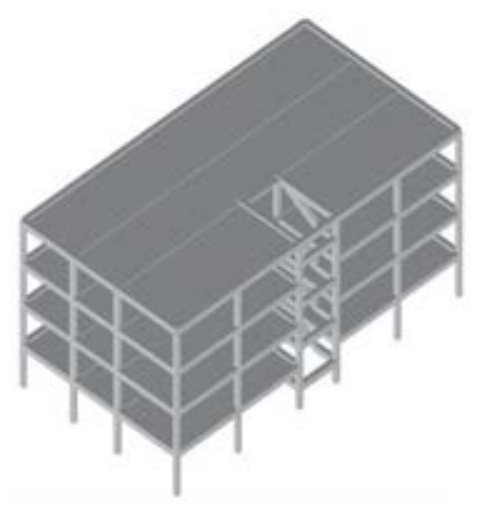

b)

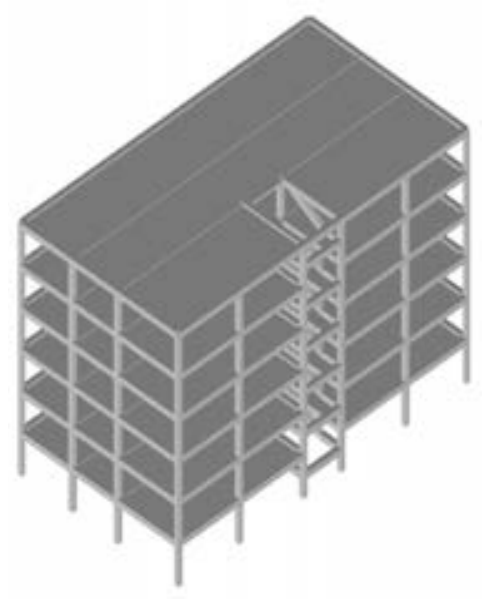

c)

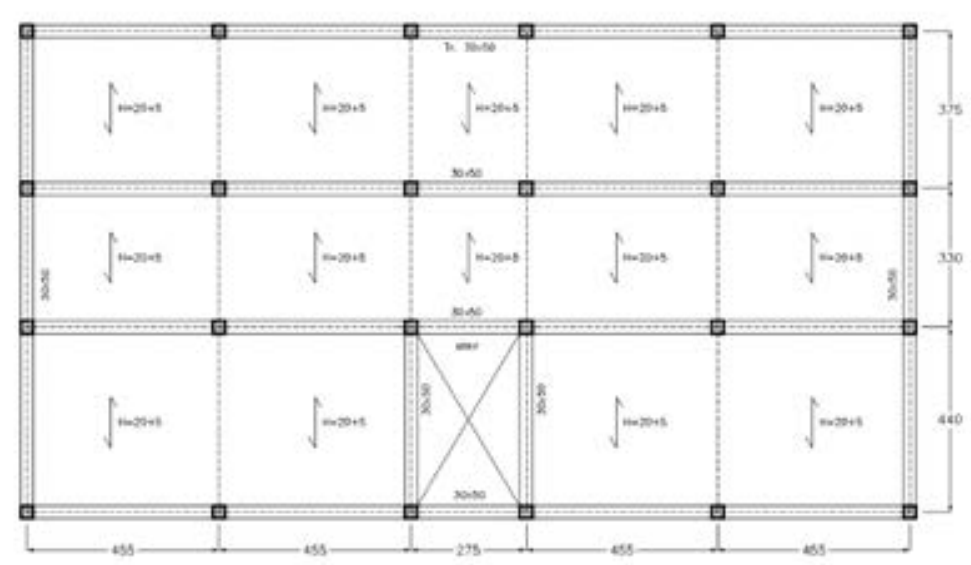

e)

Figure 2: 3D view of 2 storey (a), 4 storey (b) and 6 storey (c), and in-plane layout of 2 storey (d), 4 storey and 6 storey (f) types (from Masi et al. [5]) 
A special attention has been paid to the selection of representative ground motion records for Non-Linear Dynamic Analyses (NLDAs). Specifically, a large set of real signals consistent with the Italian seismic hazard for soil condition consistent with $\mathrm{A} / \mathrm{B}$ categories according to DM 17/01/2018 [20] has been selected and considered in terms of Peak Ground Acceleration (PGA). Although more effective Intensity Measures (IMs) could have chosen (e.g., [21]), PGA represents the best compromise between a good correlation with the non-linear seismic response and practical constraints (i.e., data available from the Italian hazard map and standards of the IRMA platform). The considered signals with increasing intensity levels allow to reach all the EMS-98 damage levels [22] with an adequate number of data. Note that, for higher intensity levels (i.e., PGA values higher than $0.5-0.6 \mathrm{~g}$ ), a spectral matching procedure of real recorded motions has been adopted [23].

According to the lognormal cumulative distribution functions employed to define FCs, the standard deviation of the natural logarithm of the considered IM has been used to describe the total variability associated with a given damage level. In this framework, the overall uncertainty

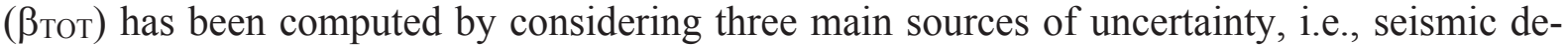
mand $\left(\beta_{\mathrm{D}}\right)$, inter/intra building capacity $\left(\beta_{\mathrm{C}}\right)$ and damage thresholds' definition $\left(\beta_{\mathrm{DS}}\right)$, and combined through a square root sum-of-the-squares (SRSS) rule, as follows:

$$
\beta_{T O T}=\sqrt{\beta_{D}^{2}+\beta_{C}^{2}+\beta_{D S}^{2}}
$$

Since $\beta_{D}$ is directly evaluated from NLDAs as a function of the selected ground motion records, for the other sources of uncertainty (i.e., $\beta_{\mathrm{C}}$ and $\beta_{\mathrm{DS}}$ ), suitable (deterministic) values from literature (e.g., [24]) and consistent with the Italian context have been considered.

In order to derive analytical FCs, the maximum interstorey drift (IDR) value along the height has been considered as earthquake demand parameter (EDP). From each NLDA, IDR value along the two in-plan directions has been evaluated and referred to the corresponding PGA value. For IDR value falling into a given damage level as defined according to a suitable relationship between damage levels and interstorey drift values, the median and the logarithmic standard deviation of the PGA value have been evaluated. An example of the relationship adopted for GLD building types is shown in Table 1 [21].

\begin{tabular}{|c|c|c|c|c|c|c|}
\hline \multirow{2}{*}{$\begin{array}{c}\text { EMS-98 } \\
\text { definition }\end{array}$} & D0 & D1 & D2 & D3 & D4 & D5 \\
\cline { 2 - 7 } & $\begin{array}{c}\mathrm{SD}=\text { null } \\
\mathrm{NSD}=\text { null }\end{array}$ & $\begin{array}{c}\mathrm{SD}=\text { null } \\
\mathrm{NSD}=\text { slight }\end{array}$ & $\begin{array}{c}\mathrm{SD}=\text { slight } \\
\mathrm{NSD}=\text { moderate }\end{array}$ & $\begin{array}{c}\mathrm{SD}=\text { moderate } \\
\mathrm{NSD}=\text { heavy }\end{array}$ & $\begin{array}{c}\mathrm{SD}=\text { heavy } \\
\mathrm{NSD}=\text { very heavy }\end{array}$ & Destruction \\
\hline $\begin{array}{c}\text { Interstorey } \\
\text { drift (\%) }\end{array}$ & $<0.1$ & $0.1-0.25$ & $0.25-0.5$ & $0.5-1.0$ & 1.02 .5 & $>2.5$ \\
\hline
\end{tabular}

Table 1: Relationship between damage levels and interstorey drift values adopted for mid- and high-rise GLD buildings (from Masi et al. [21])

Finally, the FC related to a given damage level has been obtained by applying the wellknown expression [24]:

$P(D k \mid P G A)=\Phi\left[\frac{1}{\beta_{D, D k}} \cdot \ln \left(\frac{P G A}{\overline{P G A}_{D k}}\right)\right] \quad k=1, \ldots, 5$

where $\mathrm{P}(\mathrm{Dk} \mid \mathrm{PGA})$ is the probability of exceedance of the $k$-th damage level Dk given a PGA value, $\Phi$ is the standard normal (Gaussian) cumulative distribution function, $\beta_{\mathrm{D}, \mathrm{Dk}}$ and $\overline{\mathrm{PGA}}_{\mathrm{Dk}}$ denote the logarithmic standard deviation and median values, respectively. Note that $\beta_{\mathrm{D}, \mathrm{Dk}}$ 
accounts for only the record-to-record variability as obtained from the NLDAs. In order to consider all sources of uncertainty, the values related to $\beta_{\mathrm{C}}$ and $\beta_{\mathrm{DS}}$ have to be added according to expression (1). Finally, in order to avoid unrealistic shapes of FCs (e.g., the intersection of the curves relevant to different damage levels), for each building type, $\beta$ тот value has been evaluated as the mean of the results from each damage level.

\section{ANALYSIS OF RESULTS}

On the basis of the proposed methodology, fragility curves (FCs) for all the typological classes described previously have been derived. For sake of brevity, in the present paper only the FCs for the four-storey (4s) building type designed according to the 1970's standards have been shown. Results have been analyzed in order to highlight the role of some parameters such as infill arrangement and design level on seismic fragility. FCs related to the considered parameters (i.e., GLD and ERD design levels, presence/arrangement of infills according to BF, IF and PF configurations) are shown in Figure 3, as follows:

- GLD-BF in Figure 3a;

- ERD-BF in Figure 3b;

- GLD-IF in Figure 3c;

- $\quad$ ERD-IF in Figure 3d;

- GLD-PF in Figure 3e;

- ERD-PF in Figure 3f.

In the same figure, results in terms of median value of PGA (denoted as $\theta$ and corresponding to the previously described $\left.\overline{\mathrm{PGA}}_{\mathrm{Dk}}\right)$ and dispersion $(\beta$, corresponding to the overall uncertainty $\beta_{\text {тот }}$ described above) for each damage level are reported. First of all, $\beta$ values are in the range 0.58-0.67, with higher values for GLD types and lower ones for ERD. Further, for these latter types, similar values equal to about 0.58 are found. As for $\theta$ values, the first damage level (D1) is reached at about $0.1 \mathrm{~g}$, irrespective of both design level and infill configuration, while greater differences are found for higher damage levels. In order to emphasize the role of the design level, Figure 4 shows a comparison in terms $\theta$ values evaluated for each damage level. As expected, ERD types show better performance than GLD ones, especially for higher damage levels. Specifically, for IF configuration (Figure $4 \mathrm{~b}$ ), $\theta$ value related to D5 (global collapse) is $0.96 \mathrm{~g}$ for ERD and $0.69 \mathrm{~g}$ (about $-30 \%$ ) for GLD. It is worth noting that, for lower damage levels (i.e., up to D3), similar $\theta$ values are obtained for both ERD and GLD. This result mainly depends on two factors, that are i) no infill damage prevention design was required by the code considered for ERD types, thus providing a similar lateral stiffness value between ERD and GLD, ii) the same type of infills was adopted for both ERD and GLD types. These aspects are also confirmed from the results obtained for BF type, for which similar $\theta$ values are found up to D2. The better performance of ERD with respect to GLD is even more emphasized in case of PF configuration. Indeed, the PGA median value at D5 evaluated for ERD type is approximately two times higher than for GLD type $(0.86 \mathrm{~g}$ and $0.45 \mathrm{~g}$, respectively for ERD and GLD). 


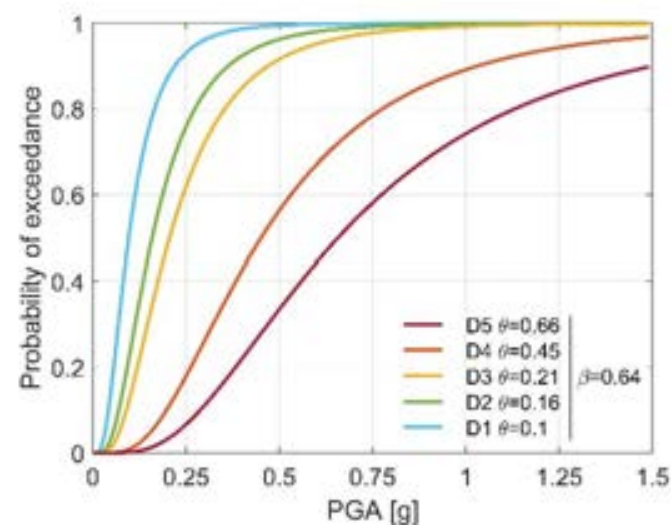

a)

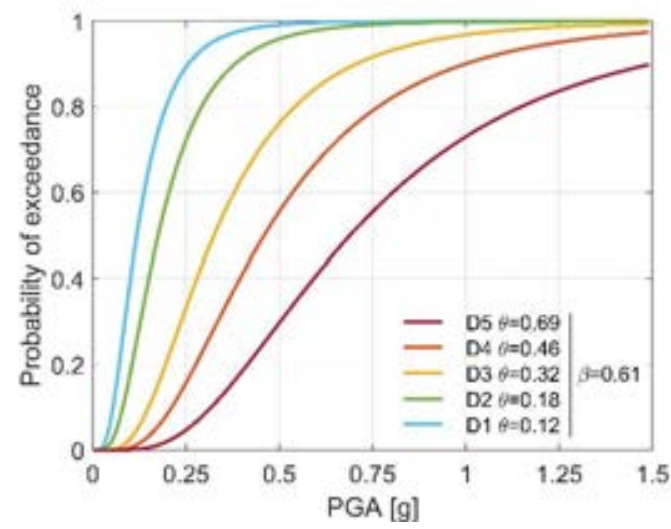

c)

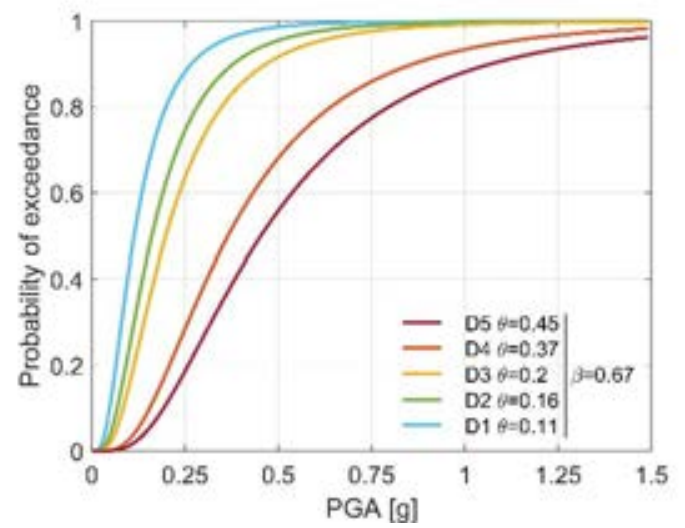

e)

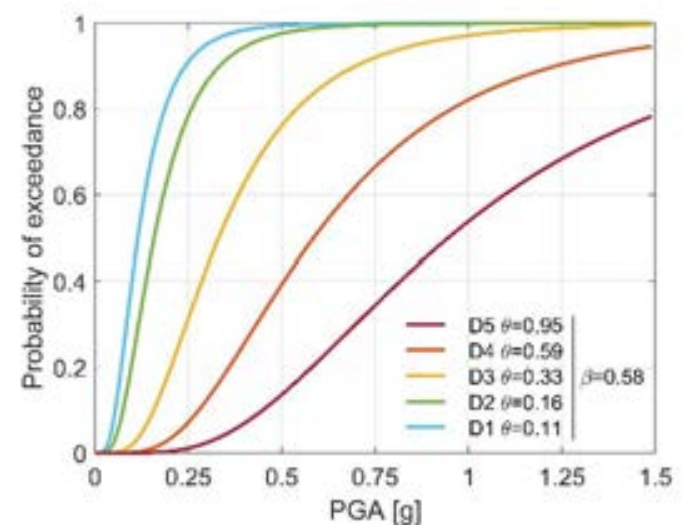

b)

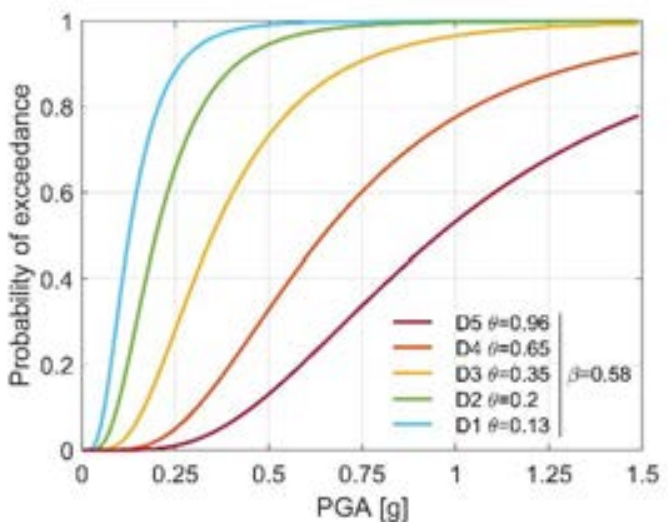

d)

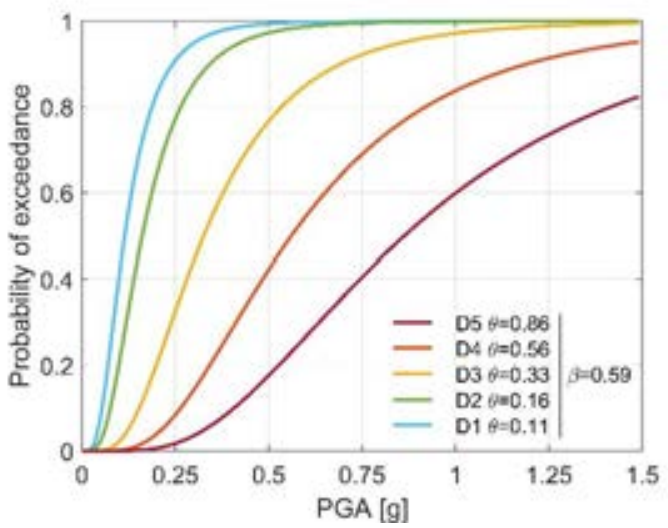

f)

Figure 3: Fragility curves for the considered building types: GLD-BF (a); ERD-BF (b); GLD-IF (c), ERDIF (d), GLD-PF (e), ERD-PF (f)

In order to highlight the role of infills on seismic performance, a comparison in terms of PGA median value by varying presence/arrangement of infills is shown in Figure 5a, for GLD type, and Figure 5b for ERD one. In general, IF types have better performance than PF ones, while intermediate results are found for BF. For GLD types, infills regularly arranged remarkably increase $\theta$ values, especially for higher damage levels. On the contrary, for all damage levels, lower differences between IF and PF are found in case of ERD types. For example, for D5 evaluated for GLD, $\theta$ value is equal to $0.69 \mathrm{~g}$ for IF and $0.45 \mathrm{~g}$ (about $-35 \%$ ) for PF. In case of ERD, $\theta$ value related to IF is $0.96 \mathrm{~g}$ while it is equal to $0.86 \mathrm{~g}$ (about $-10 \%$ ) for PF. 


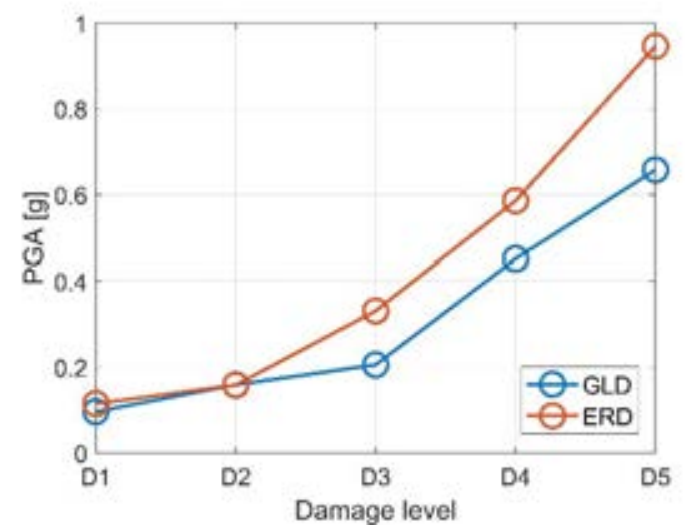

a)

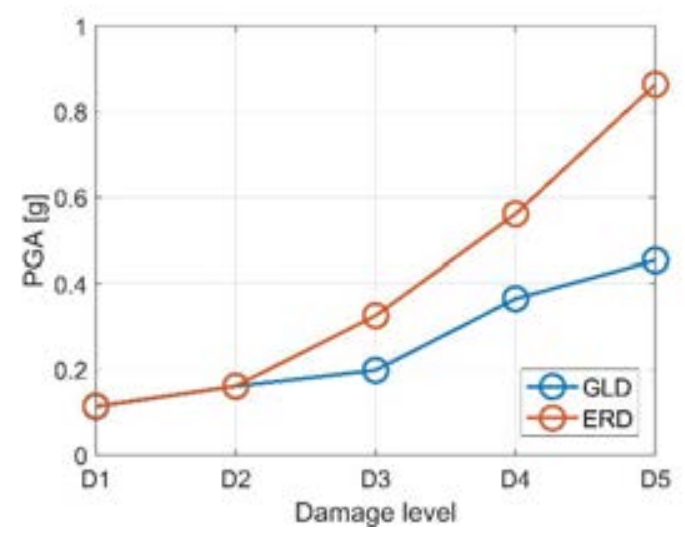

c)

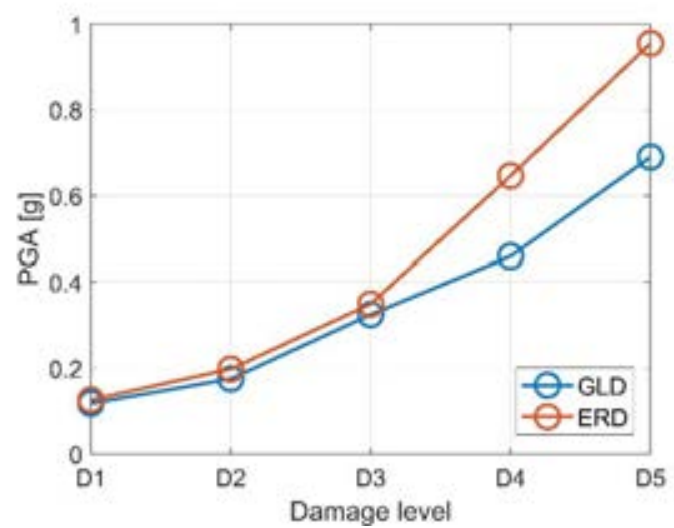

b)

Figure 4: Comparison in terms of design level (GLD vs ERD) for BF (a), IF (b) and PF (c) configurations

It is also noteworthy that, for higher damage levels, IF and BF types show similar seismic performance. Specifically, $\theta$ values evaluated at collapse (D5) are equal to $0.69 \mathrm{~g}$ and $0.66 \mathrm{~g}$ for GLD-IF and GLD-BF, respectively, and 0.96g and 0.95g for ERD-IF and ERD-BF. To this purpose, it should be recalled that infills are very brittle components whose contribution to the lateral capacity of buildings decreases at higher IDR values associated with D4 and D5 damage levels.

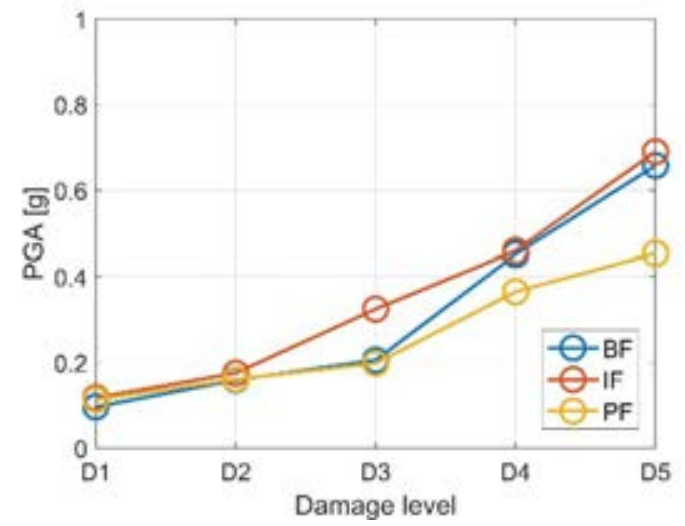

a)

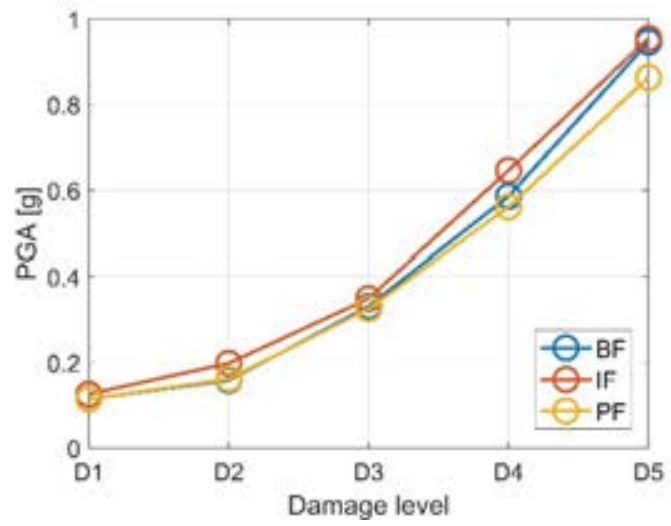

b)

Figure 5: Comparison in terms of presence/arrangement of infills for GLD (a) and ERD (b) building types 


\section{FINAL REMARKS}

Within the Work Package WP4-MARS of the 2019-2021 DPC-ReLUIS research project, one of the main goals is to enrich the vulnerability models adopted in the 2018 National Risk Assessment by deriving additional fragility curves (FCs) from different approaches. In this context, a large set of analytical FCs through non-linear dynamic analyses has been obtained by considering some prototypes representative of the Italian building stock. Four main parameters have been considered to identify building classes, that are: (i) period of construction (three periods: '50s, '70s and '90s), (ii) design level (two levels: gravity load design, GLD, and earthquake resistant design, ERD), (iii) number of storeys (three heights: Low-rise, Mid-rise and High-rise), and (iv) infill arrangement (three configurations: Regularly Infilled-frame, IF, Pilotis-frame, $\mathrm{PF}$, and Bare frame, BF).

In the paper, after a short description of the methodology, analytical FCs for the 4-storey RC building types designed according to 1970's standards have been analyzed in order to highlight the role of some parameters affecting seismic vulnerability, and specifically design level and infill arrangement.

As expected, although the '70s ERD types were poorly designed for lateral loads, significant differences (about 30\%) in terms of PGA median values at collapse (D5) have been found between ERD and GLD types. On the contrary, similar performance has been found for the lower damage levels according to the EMS-98 classification (i.e., D1 and D2). This latter result mainly depends on two factors, that are: (i) no infill damage prevention design was required by the code considered for the ' 70 s ERD types, thus providing a similar lateral stiffness value between ERD and GLD, (ii) the same type of infills was adopted for both ERD and GLD types in the '70s.

The presence of infills regularly arranged improves seismic performance, especially for buildings designed only for gravity loads (GLD type). As an example, for D5 damage level, PGA median value is equal to $0.69 \mathrm{~g}$ for IF types, and $0.45 \mathrm{~g}$ for PF ones, with a reduction around $35 \%$. On the contrary, lower differences (about 10\%) have been found in case of ERD types. The comparison between IF and BF types shows that the infill contribution to the lateral capacity of buildings is more appreciable for lower damage levels while, due to the brittle behaviour of infills, it becomes negligible at collapse.

\section{ACKNOWLEDGEMENTS}

The work reported in this article has been developed under the financial support of the Italian Department of Civil Protection, within the ReLUIS-DPC 2019-21 Research Project, WP4 Seismic Risk Maps (MARS), which is gratefully acknowledged. 


\section{REFERENCES}

[1] Italian Civil Protection Department (DPC), National Risk Assessment 2018. Overview of the potential major disasters in Italy. Updated December 2018

[2] M. Dolce, A. Prota, B. Borzi, F. da Porto, S. Lagomarsino, G. Magenes, C. Moroni, A. Penna, M. Polese, E. Speranza, G.M. Verderame, G. Zuccaro, Seismic Risk Assessment of residential buildings in Italy, Bulletin of Earthquake Engineering, https://doi.org/10.1007/s10518-020-01009-5, 2020

[3] B. Borzi, M. Onida, M. Faravelli, D. Polli, M. Pagano, D. Quaroni D, A. Cantoni, E. Speranza, C. Moroni, IRMA platform for the calculation of damages and risks of residential buildings, Bulletin of Earthquake Engineering, https://doi.org/10.1007/s10518-02000924-x, 2020

[4] M. Dolce, E. Speranza, F. Giordano, B. Borzi, F. Bocchi, C. Conte, A. Di Meo, M. Faravelli, V. Pascale, Observed damage database of past Italian earthquakes: the Da.D.O. webgis. Bollettino di Geofisica Teorica e Applicata, 60(2): 141-164, 2019

[5] Masi, S. Lagomarsino, M. Dolce, V. Manfredi, D. Ottonelli, Towards the updated Italian seismic risk assessment: exposure and vulnerability modelling. Bulletin of Earthquake Engineering, https://doi.org/10.1007/s10518-021-01065-5, 2021

[6] M. Polese, M. Gaetani d'Aragona, A. Prota, Simplified approach for building inventory and seismic damage assessment at the territorial scale: an application for a town in southern Italy, Soil dynamics and earthquake engineering, 121 (2019) 405-420, 2019

[7] G. Nicodemo, Exposure modelling and loss estimation for seismic risk assessment of residential buildings: innovative methods and applications, $\mathrm{PhD}$ thesis, University of Basilicata, Italy, http://hdl.handle.net/11563/146804, 2021

[8] ISTAT, Italian National Institute of Statistics (2011) $15^{\circ}$ Censimento della popolazione e delle abitazioni, available at http://www.istat.it

[9] G. Nicodemo, M. Pittore, A. Masi, V. Manfredi, Modelling exposure and vulnerability from post-earthquake survey data with risk-oriented taxonomies: AeDES form, GEM taxonomy and EMS-98 typologies. International Journal of Disaster Risk Reduction, 50, 101894. doi.org/10.1016/j.ijdrr.2020.101894, 2020

[10] G. Zuccaro, M. Dolce, D. De Gregorio, E. Speranza, C. Moroni, La scheda CARTIS per la Caratterizzazione Tipologico-Strutturale dei Comparti Urbani costituiti da edifici ordinari: valutazione dell'esposizione in analisi di rischio sismico. Proceedings of the $34^{\text {th }}$ GNGTS, Trieste, 2015, 2015 (in Italian).

[11] V. Manfredi, A. Masi, Seismic Strengthening and Energy Efficiency: Towards an Integrated Approach for the Rehabilitation of Existing RC Buildings. Buildings 8.3, 36, 2018.

[12] A. Masi, Seismic vulnerability assessment of gravity load designed R/C frames. Bulletin of Earthquake Engineering, 1(3), 371-395, 2003.

[13] F. McKenna, OpenSees: a framework for earthquake engineering simulation. Computing in Science \& Engineering, Vol. 13, Issue 4, pp 58-66, 2011.

[14] P. Ricci, V. Manfredi, F. Noto, M. Terrenzi, M.T. De Risi, M. Di Domenico, G. Camata, P. Franchin, A. Masi, F. Mollaioli, E. Spacone, G.M. Verderame, RINTC-e: Towards seismic risk assessment of existing residential reinforced concrete buildings in Italy, 
COMPDYN 2019, 7th ECCOMAS Thematic Conference on Computational Methods in Structural Dynamics and Earthquake Engineering, M. Papadrakakis, M. Fragiadakis (eds.) Crete, Greece, 24-26 June, 2019

[15] L.F. Ibarra, R.A., Medina, H., Krawinkler, Hysteretic models that incorporate strength and stiffness deterioration. Earthquake engineering \& structural dynamics, 34(12), 14891511,2005

[16] H. Sezen, Seismic Response and Modeling of Reinforced Concrete Building Columns. Ph.D. Thesis, Department of Civil and Environmental Engineering, University of California, Berkeley, CA, USA, 2002.

[17] G.M. Verderame, P. Ricci, M. Esposito, G. Manfredi, STIL v1.0 - Software per la caratterizzazione delle proprietà meccaniche degli acciai da c.a. tra il 1950 e il 2000. ReLUIS, Naples, Italy, 2012. Available at http://www.reluis.it/

[18] A. Masi, A. Digrisolo, G. Santarsiero, Concrete strength variability in Italian buildings: analysis of a large database of core tests. Applied mechanics and materials, 597, 283-290, 2014.

[19] A. Masi, V. Manfredi, G. Cetraro, In-plane performance of RC infilled frames under seismic actions: Experimental versus code provision values. In Brick and Block MasonryTrends, Innovations and Challenges; Modena, C., da Porto, F., Valluzzi, M.R., Eds.; Taylor \& Francis Group: London, UK, 2016; ISBN 978-1-138-02999-6.

[20] Ministrial Decree 17 January 2018, NTC 2018. Aggiornamento delle "Norme Tecniche per le Costruzioni”. GU n. 42, 20 February 2018

[21] A. Masi, A. Digrisolo, V. Manfredi, Fragility curves of gravity-load designed RC buildings with regularity in plan. Earthquake and Structures 9(1):1-27, 2015

[22] G. Grunthal, European Macroseismic Scale. Chaiers du Centre Européen de Géodynamique et de Séismologie, Vol. 15, Luxembourg, 1998

[23] R. Paolucci, A.G. Ozcebe, C. Smerzini, A. Masi, V. Manfredi, Selection and spectral matching of recorded ground motions for earthquake engineering analysis, available at http://143.225.144.186:5000/, 2020

[24] Federal Emergency Management Agency (FEMA), Hazus-MH 2.1 Technical Manual: Earthquake Model, developed by Federal Emergency Management Agency, Mitigation Division, Washington, D.C., 2012 